\title{
Support of Mobile Phones in a Private Network for Science Teaching
}

\author{
http://dx.doi.org/10.3991/ijim.v10i2.4817 \\ Sakunthala Yatigammana Ekanayake, Kamalanath Samarakoon \\ University of Peradeniya, Peradeniya, Sri Lanka
}

\begin{abstract}
The potential of mobile phones to facilitate students' science learning, when they are engaging in group activities, was investigated. To minimize the disciplinary issues emerged from the previous research on mobile devices and to enhance the quality of learning, a set of mobile phones that are connected to a private network was used. The lesson planning and implementation through these mobile phones were facilitated by a web based Application. A purposively selected group of teachers developed three lessons while integrating mobile phones in a private network into learning activities. Then the lessons were implemented in real classroom settings. This paper is based on one of the lessons 'Waves and their Characteristics' that was implemented for Grade 11 students. The data were collected through observations using audio, video and field notes and were analyzed using thematic analysis technique with the help of NVivo10 qualitative data analysis software. Based on the thematic analysis, two assertions were derived. Notably teachers appreciated the support of the private network in enhancing the quality of group learning activity while minimizing the students' misuse of mobile phones.
\end{abstract}

Index Terms-Mobile learning, Science education.

\section{INTRODUCTION}

Most researchers and science educators agree that students must not only know a body of information about science, but also they must be able to do a range of scientific tasks and processes. Elaborating this further, Reference [1] claims that science education consists of two components: the content and the processes. The content of science includes laws, facts, and theories, and the processes of science consist of observing, measuring, recording, processing data, hypothesizing, communicating and discussing, investigating, trying things out, handling things, watching and monitoring [2]. Considering the teaching of science, in order to support students' science learning, two interrelated areas, namely understanding of content and processes should be developed [3]. Furthermore, it is well recognized that what students learn is greatly influenced by how the students learn. Many students learn best through small group work inside and outside the classroom that foster active collaboration. The investigative nature of science provides a unique setting for group work. However, this nature of science is an aspect often neglected by science teachers in their normal teaching [4]. Moreover, according to the research findings on teaching of science, doing science practical that fosters the investigative nature of science is not an easy task for teachers. This is due to reasons such as inadequate resources in schools, large number of students in a class and the difficulty of facilitating and guiding of many groups by a teacher. Therefore, it is worthwhile to explore the possibil- ities of providing opportunities for students to learn science as group activities while overcoming the above mentioned difficulties. This paper describes a study where mobile phones on a private network were used in enhancing science learning through group activities. This paper first examines the related literature, and then describes the methodology, results and discussion, followed by limitations and future research.

\section{Mobile Phone As A Teaching LeARning ToOL}

\section{A. Potential of mobile devices}

Science teaching is complex, as the processes involved in teaching as well as learning science cannot be reduced to a series of algorithms that applicable to all educational settings [5]. While referring to the content of science, Reference [6] claims that science is not an archive of facts, but a complex set of theories, laws and so forth that we use to model the world. Furthermore, science involves abstractions, difficult ideas and theoretical entities that cannot be seen or handled [7]. However, according to the literature, the integration of different technologies into science classroom teaching has been facilitating science teaching as well as science learning. This is because instead of the previous unidirectional transfer of information from teacher to student, the use of ICT can provide opportunities for students' active learning by providing new pedagogical models that allow the learner to access and digest information more independently [8]. Furthermore, ICT opens up new opportunities in science teaching and learning by offering fresh approaches, such as providing access to vast amounts of up-to-date information [9, 10], running a simulation to test a prediction, clear and effective ways of presenting scientific information, thus enhancing students' understanding of scientific concepts [11, 12]. Moreover, the rapid diffusion of computers together with the internet and other ICT resources can make teaching and learning processes effective and interesting [11, $13,14]$.

Among the myriad of ICT resources mobile devices are unique. The increased ownership of mobile devices by both teachers and students has added an opportunity for innovation with respect to teaching and learning in schools. Emphasizing this, Reference [15] claims that the mobility provided by mobile devices create opportunities for new forms of technology supported learning since it changes the nature of the physical relationships among teachers, learners, and the objects of learning. By reviewing the studies reported in the recent research literature, Reference [16] identifies that mobile devices offer considerable benefits and opportunities to build and support 
creative, collaborative, critical, and communicative capacities of students within learning environments.

It is recognized that the potential of mobile phones to support learning is both due to their range of functions that include Short Messaging Service (SMS), Multimedia Messaging Service (MMS), video, camera, the Internet, voice recording and Bluetooth and their attributes such as being personal, informal, contextual, portable and ubiquitous [17]. Due to the personal and portable attributes of mobile devices there is a potential for creating new forms of interactions in the learning process and its surroundings. Furthermore, it provides an individual learning experience for learner while increasing ownership and the responsibility of learning [18]. Relating to the inherent social feature of mobile devices, Reference [19] finds that the portability of mobile devices enhances group work and communication within educational settings by enabling rich social interactions. In terms of the functions of mobile phones, the present-day mobile phones are complete multimedia centres that combine the capabilities of a still and video camera, a personal organizer and a web browser in one device [20]. The image function of mobile phone supported bringing the outside world into the classroom making use of authentic contexts and students' science learning personally relevant [21].

\section{B. Possible issues of using the mobile phone as a teaching learning tool}

Even though the mobile phones enhance students science learning, most of the times teachers have concerns about the possibility of students' misuse of the mobile phones during learning activities. There are incidents reported in the literature where the mobile phone is considered a threat to the teaching and learning process. In India, the Maharashtra Government has banned the use of mobile phones in public and private schools up to class 10 across the state [22]. The Guardian Newspaper in the UK states that mobile phone is " a potentially potent tool for learning but strangely feared in a school pupil's hand, where it is assumed to wreak havoc with concentration, unleash cyber bullying and surreptitiously video up teachers' skirts." The Sri Lankan Government banned students from taking mobile phones to schools in 2009.

Another issue that prevent the use of mobile phone for teaching and learning is cost associated with it. In a study, which was focused on the readiness of Sri Lankan science teachers' towards the use of mobile phone in teaching and learning [23], it was reported that even though the use of mobile phones in science teaching and learning is useful and timely, paying bills would be a big problem.

One participant suggested an alternative way of managing the cost as:

"All the students do not have mobile phones and school can't afford to buy mobile phones for all the students and pay the bills. However, if a school... I mean a lab can have a certain number of mobile phones like computers or other equipment in the lab.... then teacher can use them when implementing a lesson.",

(Interview 2)

\section{A possible solution - Mobile Phone in a Private Network}

A set of mobile phones that are belonging to the school and connected to a private network was used for this study. These mobile phones have neither a SIM (Subscriber Identity Module) nor contract with commercial cellular company. This is advantageous, as students cannot misuse the mobile phone by taking calls or browsing the Internet. Furthermore, the use of mobile phones without a SIM and/or a contract eliminated the operating cost.

In order to create a private network and to support learning activities a faster Wi-Fi based WLAN was used. Since the use of WLAN technology to access the Internet through a wireless router is already well established and matured, the web-based technology was selected. This selection ease the development of Applications as the Application sharing is already facilitated through web browsers.

A teaching and learning IT environment consists of four web Applications namely MobileAdmin, MobileLesson, MobileTeacher and MobileStudent were developed to set up the learning activities. First three Applications are for teachers and the MobileStudent Application is for students. These Applications were developed using PHP. A MySQL database is implemented to store data required for these Applications.

The database comprises of tables to store user data and lesson data. Users can be Application administrators, teachers and students. A lesson comprised of sections, pages and fields with one-to-many relationships. A field can be one of nine different types. These types are image, video, text, heading, audio, html, upload and sendmessage. First seven fields are described by the field type and a file name. The files designated by the filenames are stored in a predefine location of the server. These files have the information that should be presented to the student when they are visiting each page.

The MobileAdmin Application facilitates to create teachers and students as users of this learning ICT system. This Application is also used to define lessons. Teachers use MobileAdmin Application to define lessons. Fig. 1 shows the screen that allows teachers to define a lesson. A section comprise of one or many pages for which students can visit at a time. One page comprises of many fields that are displayed in a single page. Students can navigate between the pages in a section many times until they are familiar with or complete the instructions given in a section of a lesson. MobileTeacher facilitates to conduct the lessons according to the lesson plan defined using $\mathrm{Mo}$ bileAdmin. Along with the students details, the information about the section on which a students should work, whether a student has started to work in the section and the page on which a student is working are displayed. Usually a lesson is planned such that a section has one or more feedback. Based on the feedback, teacher allows a student to proceed to next section by pressing a button or teachers physically intervene and help student to complete the section.

\section{LESSON DESIGN AND IMPLEMENTATION}

This exploratory study seeks the possibilities of using mobile phones in a private network in science teaching and learning. A purposively selected group of 18 Sri Lankan science teachers who already learned about the educational potential of mobile phones and the ways of integrating mobile phones into science teaching designed the lessons participated in this study. Initially, the proposed private network and the web based Applications 


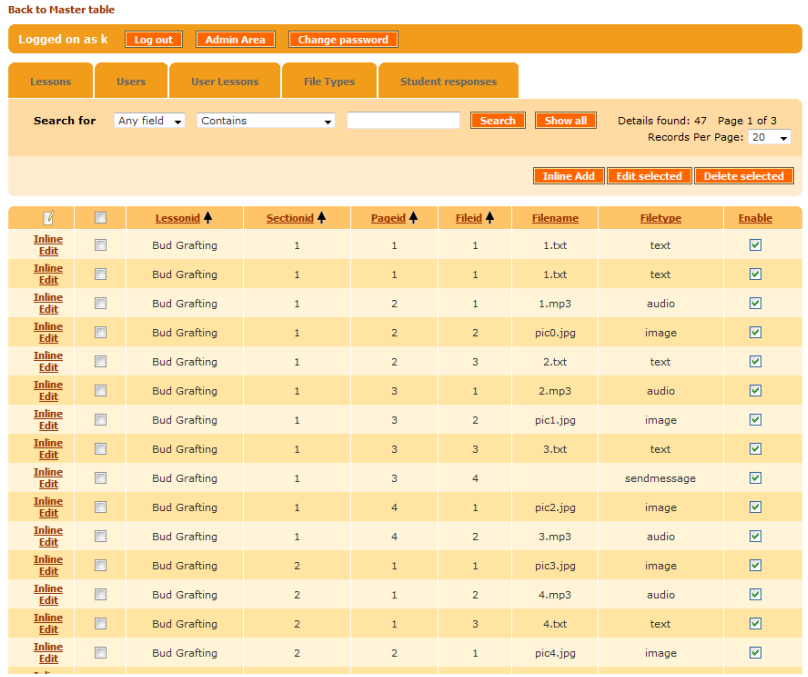

Figure 1. A lesson defined in MobileAdmin Application

were introduced. Then they were given a hands-on session where they could access the web server in the private network using a set of mobile phones provided to them and run different Applications.

Working together in small groups, the teachers selected three science lessons from the Sri Lankan national science curricula for grades 6 to 11 where the concept of mobile phones in a private network could effectively be utilized. The participants drafted their lesson plans for the lesson they had selected and tested whether the mobile phones would fulfill their expectations for the planned activities. Then they were given one week to develop a concrete set of instructions for lesson implementation. Then the designed lessons were role-played by a member of a group while the others acted as students. At the end of role-play of each lesson, there was a whole group discussion about the particular lesson. During these discussions, the pedagogical practices as well as the ways of using the mobile phone in a private network to support these practices were critically evaluated. Based on the feedback received for each lesson the lesson plans were fine tuned. Next, the lessons were implemented in three schools, each by one of the teachers from each group.

There was a Review Workshop after the lesson implementation. During the Review Workshop the three presenting teachers first presented their experiences, reflections and thoughts about the use of the mobile phones in a private network in science teaching and learning. This workshop provided opportunities for all the participants to present and discuss their experiences, reflection.

This paper is based on one of the lessons namely 'waves and their characteristics' for Grade 11 students. The lesson was planned such that initially teacher taught basics of waves and then students were directed to the mobile phone based group activity. Prior to starting the group activity, students were explained about the learning platform and how to use it. Then they were given a time to get used to this system.

During the group activity, each student group was given two mobile phones. One carried an App called 'Oscilloscope' and the other was connected to a private network where student groups accessed the material related to the activity. An instruction sheet with the instructions given in Appendix was given to each student group. Once the se-
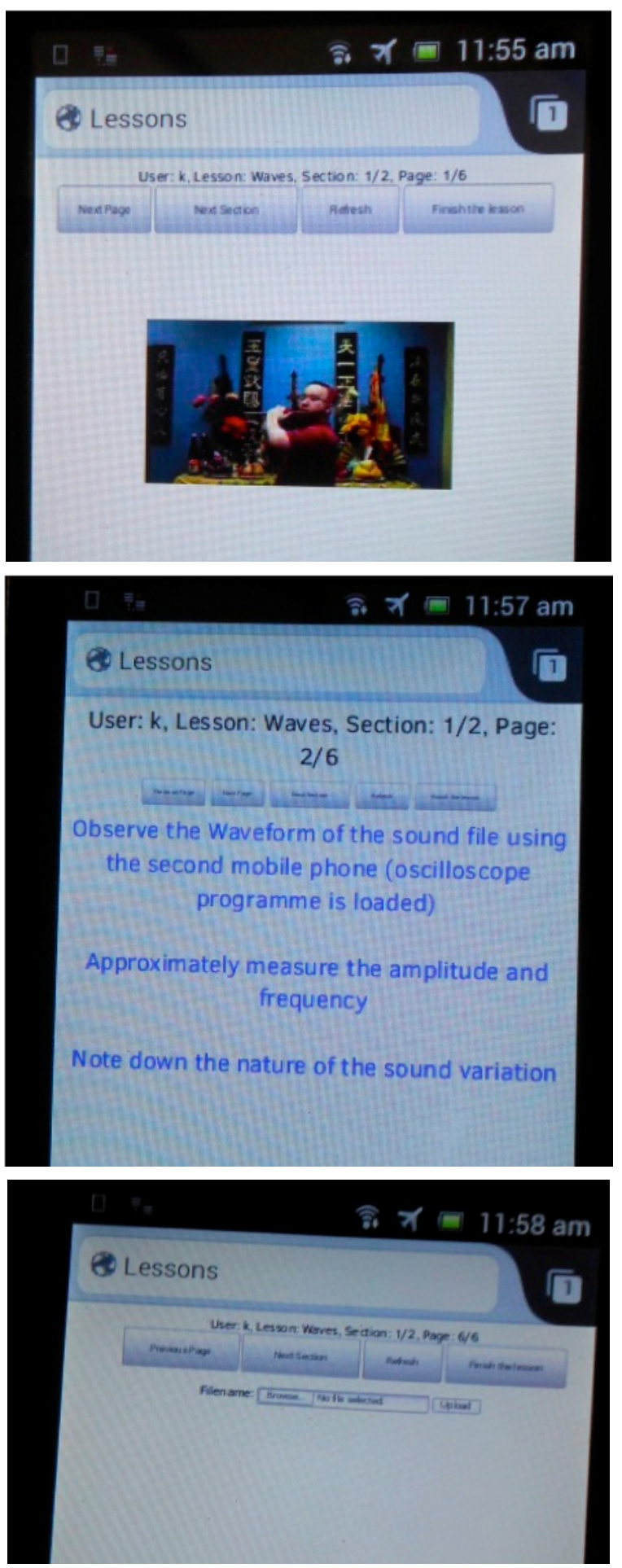

Figure 2. Screen shot from the mobile phones

cond mobile phone was connected to the private network it gave step-by-step instructions. Some instructions are shown in the screenshots given in Fig. 2. Students followed these instructions and carried out the lesson. Breaks were introduced to the lesson after some tasks and in order to move forward students were asked to send an image to teacher's computer. Upon receiving the image teacher examined it and gave permission to move forward.

Upon completion of the group activity, the teacher used the images send by student groups to discuss the salient characteristics of waves. 


\section{DATA COLLECTION ANALYSIS}

During the Planning Workshop, lesson implementation and the Reviewing Workshop, data were collected using observation via video, audio recording and written materials (teachers' notes from lesson planning, the participant observer's field notes and students' comments in postlesson interviews). These data were transcribed, translated into English if necessary and analyzed using Thematic Network Analysis [24] technique with the support of NVivo10 qualitative data analysis software. In order to analyze the data, the paper based material were first translated and entered into the NVivo10 software. After that, all the video and audio files were also uploaded without transcribing or translating as NVivo10 enables researchers to transcribe audio and video data while playing them.

\section{FINDINGS AND DISCUSSION}

Based on the thematic analysis described above, two assertions were derived. They are 'the private network is welcome by both the teachers and students' and 'mobile phone supported science teaching and learning'.

\section{A. The private network is welcome by both the staff and students:}

It was observed that the teacher who conducted the lesson as well as the students were impressed about the added value of the private network in order to make the leaning activity fruitful. During the review session, the teacher who conducted the lesson stated that she could send the instructions to each and every student group step by step due to the fact that the mobile phones were connected. Further, she reported happily that the easiness of implementing the learning activity without any concerns regarding the students' misuse of the mobile phone as she could check whether the students were engaging in the activity through her laptop computer. Another teacher who contributed to the development of the lesson further emphasized how the schedule of the lesson with the private network supported teacher in this supervision as follows:

"As we scheduled all the steps in the learning activity while practically doing each of them, we could decide the time that would need to accomplish each and every step. Thus, the teacher who conducted the lesson could identify a delay of a particular group and could examine it."

(Teacher 2/Review session)

It was also noted that the students were all engaged in the activity while focusing on the tasks as after completion of some tasks students had to send their results to the teacher via the network. Especially the data revealed that the students wanted to get the best result and send it to the teacher's computer while following the step by step instructions properly.

Another important point that the teacher highlighted during the reviewing session was the possibility of using the private network, without any cost for these type of a group learning activity. Adding more views to that another teacher from a different group compared this network with the computer network in the computer room as follows:

"Even though we use networked computers in the school computer room that environment is not good as this. I mean a computer network can only be used inside the classroom. As the computers are fixed students cannot work in groups. Further, we do not have access to the computer room when we want."

(Teacher 11/Review session)

Furthermore, another teacher appreciated the possible mobilization of the private network system where group activities can be done outside the four walls of the classroom. Besides these, the teacher who conducted the lesson valued the possibility of accessing students during the lesson implementation as well as any convenient time for her as most of the students' observations and results were saved in her computer as well as in the mobile phones.

The data also revealed the students' comments about the mobile phones on a private network. They appreciated the receiving of step by step instructions and the possibility of revising them going backward and forward by pressing a button when they needed. One student's view was:

"As we received the instructions step by step we could read and understand them while discussing any doubts as a group".

(student /interview)

Another student said that as they could not go to the further steps without sending what they had to send to the teacher at some steps, made their learning successful. Another student said as a fact of this they fully engaged in learning, followed the instructions properly, and shared their skills and knowledge in order to get the correct results. In addition to these comments, another student said as follows:

"I feel like we all wanted to do each step according to the instruction because we were really curious to get the next step. The practical was so interesting."

(student /interview)

\section{B. Mobile phone supported science teaching and learning}

According to the observation, it was revealed that the mobile phone supported teachers teaching as well as students learning. The data during the lesson planning activities revealed that the mobile phone supported teachers to find and create different teaching and learning aids. One teacher reported it as follows:

"When we were thinking about the teaching/learning aid that provides a good understanding about the characteristics of a wave, mobile phone supported us a lot. Some members downloaded different resources while the others were trying to create teaching aids. Finally comparing all the alternatives we selected the particular Oscilloscope App as the most appropriate teaching aid".

(Teacher 11/Review session)

During the discussions that teacher groups were having during the planning stage, a teacher expressed the unique potential provided by the mobile phones as:

"When we are teaching the lesson on waves, often we used pictures. Students could not see the waveforms. We could use the only one oscilloscope available in the lab to show waveforms that could be generated from a signal generator. However we haven't had any facilities to show real world waveforms. The mobile phones provided a unique opportunity as we could show real world waveforms while playing the sound."

(Teacher 15/Planning session) 
The teacher who conducted the lesson said this time she could use a teaching/learning aid like oscilloscope which enhances the students' understanding, providing opportunity to the students to play different sounds, and see how the characteristics of a wave changes. Furthermore, she mentioned that in previous years she used only blackboard to describe this while drawing a wave on it.

It was noted that sending instructions via the network makes the teacher freer. Further, she could interact with the students while they were engaging in the activity as each student group have to send their results at some steps, teacher should examine the results and allowing them to go on. The teacher who conducted the lesson expressed her opinion as below;

"mm...actually when I conducted the lesson using this platform I was free because I did not want to say the instructions time to time and further explain them again and again. So I could spend most of my time to observe what each group was engaged with and facilitated them whenever required."

(Teacher 2/Review session)

During the review session, the teacher who conducted the lesson emphasized the support of the use of mobile phone for this activity. She appreciated the portable nature of the mobile phone due to which students could handle it, share their knowledge and skills among the group members when, getting correct results. Further, she said that the new platform used for this lesson created a cooperative learning environment. Moreover, she said that as she could use students' favorite technology in the classroom group activity, their active participation was enhanced compare to other group practical classes.

During the review session teachers appreciated the private network that minimizes the possible students' misuse of mobile phones.

They also commented about the students' learning with the aid of the private network and Applications used. According the field note,

"Students were so happy to see how the waves changed according to different students' voices. They really enjoyed it and experimented it during the short time period that the teacher allowed. It was a good start to the lesson while getting all students attention"

Field notes

All the group members said that they could see the characteristics of waves in reality while listening to them. They said that this was a unique experience they had during their student life. A student who participated in the lesson stated about this experience further as follows:

"During other lessons we never used mobile phones. But today our science lesson was very different. Our teacher gave mobile phones to us and asked us to use them during our group activity."

\section{(Student Comment/)}

It seemed that the students were happy about knowing the educational potential of the mobile phone during the learning activity. Another student who participated in the lesson also stated as follows:

"...due to allowing us to use mobile phone during the learning activity, our teacher showed us the educational value of the mobile phone. Otherwise, we use our mobile phones to communicate and play games. Now we know how to use it for our studies. The use of mobile phones is a new trend in the world. Therefore, we feel happy about our teacher's use of the mobile phone at today's lesson. We hope that we will be able to use mobile phones in other subjects in the future",

(Student Comment/Audio recording)

Notably, there were no negative comments from the students towards the use of mobile phones in science learning.

\section{CONCLUSIONS:}

This study shows how the use of mobile phones in science learning supported teachers in teaching in an innovative way and also cater students learning in their preferred way. Especially, the networked mobile phones created an atmosphere where the teachers could conduct the lesson in a safe way while minimizing the possible misuse of the mobile phone by students. Furthermore, as a fact of using this private network teacher could provide instructions to do the leaning activity as step by step to the students while assessing their performance, and also facilitating them when it required. The saved images (which students had recorded during learning activities) provided flexibility for teachers to assess students' science learning and to reflect on their practice at a time of their convenience. The private network and the portable nature of mobile phones enhanced students' science learning by providing a collaborative and interesting learning environment.

Clearly, there are limitations in this research where it was explored the use of mobile phones in a private network in one science lesson, in one school. Further research could broaden the understanding of the use of mobile phones in a private network by conducting lessons in different context and also for different subjects. Moreover, it would also be valuable to investigate the effectiveness of the use of the mobile phone under private network in this science lesson by comparing this lesson with same lesson conducted in traditional approach.

\section{APPENDIX - INSTRUCTIONS GIVEN TO STUDENTS}

You are given two mobile phones: MP1 and MP2. Please follow the following instructions:

a) Open the App called 'Oscilloscope' in MP1 and set the Time/Div to 1.

b) Make a 'Sha' sound by each student in the group and observe the changes in the oscilloscope display; Also experiment how to hold the waveform.

c) Now changes the Time/Div from 1 to 8 and observe the waveform while making the sound 'Sha'.

d) Using MP2 follow the instructions in Table I

e) Observe the sounds played by MP2 from the 'Oscilloscope' App in MP1. Hold the waveform and obtain the observations to fill Table II:

f) Take a photograph of this table and upload to the teacher's computer through the private network.

g) Now draw the waveform of the last sound file using Time $/$ div $=1$ and 8 in the boxes provided.

h) Take a photograph of the above plots and upload to the teacher's computer through the private network. 
TABLE I.

1. Unlock the mobile phone

2. Open firefox

3. Type $192.168 .1 .3 / \mathrm{mb} 1 / \mathrm{ln}$ in the address bar. Touch on Go

4. Enlarge the screen using the thumb and index figure tips. Follow this to enlarge the screen whenever required.

5. Open 'Student form.PHP'

6. Type the ID No and the Password (select your ID and Password)

7. Touch LOGIN

8. Type ' 3 ' in the box 'lesson No'

9. Touch on SELECT LESSON

\section{TABLE II.}

\begin{tabular}{|c|c|c|c|}
\hline Waveform & $\begin{array}{c}\text { Amplitude of } \\
\text { the waveform } \\
\text { (number of } \\
\text { divisions) }\end{array}$ & $\begin{array}{c}\text { Number of } \\
\text { cycles per } \\
\text { division }\end{array}$ & $\begin{array}{c}\text { Nature of the wave- } \\
\text { form }\end{array}$ \\
\hline 1 & & & \\
\hline 2 & & & \\
\hline 3 & & & \\
\hline 4 & & & \\
\hline 5 & & & \\
\hline
\end{tabular}

\section{ACKNOWLEDGMENT}

Authors wish to thank National Research Council of Sri Lanka who provided funding for this study. Further, the authors would like to thank the University of Peradeniya, Sri Lanka for supporting this activity, the Principal and staff of schools, for providing facilities to conduct this study, the teachers who designed and implemented the study and the students who participated in this lesson.

\section{REFERENCES}

[1] Newton, D. P. (1998). Making science education relevant. (T. Marjoram, Ed.). London: Kogan Page LtD.

[2] Wellington, J. (2004a). Multimedia in science teaching . In R. Barton (Ed.), Teaching secondary science with ICT (pp. 87-102). Berkshire.

[3] Braund, M. (2008). Starting science again? Making progress in science learning. London: Sage Publications.

[4] Wong, T. T. S. (2001). Three Main Types of Cooperative Learning in Science. Retrieved from Asia-Pacific Forum on Science Learning and Teaching

[5] Alsop, S. (2005). Motivational belief and classroom contextual factors: Exploring affect in accounts of exemplary practice. In S. Alsop, L. Bencze, \& E. Perdretti (Eds.), Analysing exemplary science teaching (pp. 146-159). Berkshire: Open University Press.

[6] Taber, K. S. (2005). Conceptual development. In S. Alsop, L. Bencze, \& E. Pedretti (Eds.), Analysing exemplary science teaching (pp. 127-136). Berkshire: Open University Press.

[7] Wellington, J. (2004b). Using ICT in teaching and learning science. In R. Holliman \& E. Scanlon (Eds.), Mediating science learning through information and communications technology (pp. 51-78). London: RoutledgeFalmer. http://dx.doi.org/10.4324/ 9780203464007_chapter_1.3

[8] Plomp, T., Pelgrum, W. J., \& Law, N. (2007). International comparative survey of pedagogical practices and ICT in education.
Education and Information Technologies , 12(2), 82-92. http://dx.doi.org/10.1007/s10639-007-9029-5

[9] Osborne, J., \& Hennessy, S. (2003). Literature review in science education and the role of ICT: Promise, problems, and future directions. Future lab (Vol. 2008). Bristol: Nesta Future Lab.

[10] Wishart, J., Ramsden, A., \& McFarlane, A. (2007). PDAs and handhelds: ICT at your side and not in your face. Technology, Pedagogy and Education, 16(1), 95-110. http://dx.doi.org/10.1080/14759390601168106

[11] Hennessy, S., Rosemary, D., Kenneth, R. \&, \& Winterbottom, M. (2007). Pedagogical strategies for using the interactive whiteboard to foster learner participation in school science. . Learning, Media and Technology, 23(6), 491-502. http://dx.doi.org/10.1080/ 17439880701511131

[12] Wellington, J. (1999). Multimedia in science teaching: Friend or foe? Journal of Physics Education, 34(6), 351-359. http://dx.doi.org/10.1088/0031-9120/34/6/403

[13] Cox, M., Webb, M., Abbott, C., Blakeley, B., Beauchamp, T., \& Rhodes, V. (2004). ICT and pedagogy: A review of the research literature. Becta (p. 43).

[14] Scrimshaw, P. (2004). Enabling teachers to make successful use of ICT. Becta ICT Research.

[15] Laurillard, D. (2007). Pedagogical forms for mobile learning: framing research questions. (N. Pachler, Ed.)Mobile Learning towards a research agenda (pp. 153-175). London: WLE Centre.

[16] Cobcroft, R., Towers, S., \& Smith, J. (2006). Mobile learning in review: Opportunities and challenges for learners, teachers, and institutions. In Online Learning and Teaching (OLT) Conference (pp. 21-30). Queensland University of Technology, Brisbane. Retrieved from http://eprints.qut.edu.au/5399/1/5399.pdf

[17] Kukulska-Hulme, A., \& Traxler, J. (2005). Mobile teaching and learning. In A. Kukulska-Hulme \& J. Traxler (Eds.), Mobile learning a handbook for educators and trainers (pp. 25-42). Oxon: Routledge.

[18] Naismith, L., Lonsdale, P., Vavoula, G., \& Sharples, M. (2004). Literature review in mobile technologies and learning. Nesta Futurelab. Retrieved from http://www.futurelab.org.uk/resources/documents/lit_reviews/Mob ile_Review.pdf

[19] Cochrane, T. (2007). Mobile blogging: A guide for educators. In mLearn2007 (pp. 28-36). Melbourne, Australia.

[20] Marriott, M. (2005). Use this phone to find a date. Or see video. Or even talk. New York Times.

[21] Ekanayake, S. Y., \& Wishart, J. (2013). Mobile phone images and video in science teaching and learning. Learning, Media and Technology, 39(2), 229-249. http://dx.doi.org/10.1080/1743 9884.2013.825628

[22] Maharashtra govt bans mobile phones in schools. Times of India, $21 \mathrm{Feb} 2009$.

[23] Ekanayake, T. M. S. S. K. Y., \& Wishart, J. (2011). Investigating the possibility of using mobile phones for science teaching and learning: Is it a viable option for Sri Lanka? International Journal for Cross-Disciplinary Subjects in Education, 2(1).

[24] Attride-Stirling. J (2001). "Thematic networks: an analytic tool for qualitative research", Qualitative Research, vol. 1(3), 385-405. http://dx.doi.org/10.1177/146879410100100307

\section{AUTHORS}

Sakunthala Yatigammana Ekanayake is with the Department of Education, University of Peradeniya, Peradeniya, Sri Lanka (syatigammana@yahoo.com).

Kamalanath Samarakoon is with the Department of Computer Engineering, University of Peradeniya, Peradeniya, Sri Lanka (kamalanath@gmail.com).

Submitted 20 June 2015. Published as resubmitted by the authors 13 August 2015.. 